Humphry Davy, rather than Benjamin Thompson, disproved the caloric theory of heat, and she seems unaware that William Thomson and Lord Kelvin are the same scientist.

In 2004, the Bibliotheca Alexandrina, the new library of the city where Napoleon landed, digitized and made available online and on CD the multi-volume Description de l'Égypte, originally issued by the French government. Meanwhile an empire-builder of the twentyfirst century was wrecking the archaeological sites and museums of another great Middle Eastern civilization.

Napoleon, for all his ruthlessness in Egypt, increased, rather than diminished, the world's intellectual heritage. The book that this extraordinary scientific adventure deserves has yet to be written.

Andrew Robinson is a visiting fellow of Wolfson College, Cambridge. His recent books include The Last Man Who Knew Everything and The Story of Measurement (Thames \& Hudson).

\title{
Size matters, sometimes
}

\section{Body Size: The Structure and Function of \\ Aquatic Ecosystems \\ edited by A. Hildrew, D. Raffaelli and \\ R. Edmonds-Brown \\ Cambridge University Press: 2007. 356 pp. $£ 35, \$ 65$}

\section{Steven Murawski}

Shakespeare had it right when he had Pericles say, "Master, I marvel how the fishes live in the sea. Why, as men do a-land; the great ones eat up the little ones." Individual body sizes of organisms in aquatic ecosystems vary by a stunning 20 orders of magnitude - from freeliving bacterial forms at $10^{-12}$ grams up to 180 tonnes for the blue whale, the largest animal ever to inhabit the planet. The distribution of animals of different sizes in a community dictates the structure and functioning of their ecosystem. For example, larger animals are much rarer than smaller ones, but they may still control the abundance of smaller plants and animals owing to factors such as their high rate of consumption and longer average lifespan.

On land, very large life forms, such as trees, can be found at the base of the food chain. Tiny organisms such as phytoplankton in the aquatic domain dominate primary production, where large predators prey on plants and animals that are a tenth to a thousandth of their own body size. Suspension feeding by straining particles suspended in the water (the aquatic equivalent of spider-web tactics) is commonplace. Parasitism, where predators are smaller than their prey, is comparatively infrequent.

Body Size: The Structure and Function of Aquatic Ecosystems focuses on size relationships between different components of aquatic ecosystems. Using this approach to interpret complex patterns provides the tools to help understand the consequences of human activity. For example, fisheries select the largest fish - with the result that top predators are harvested first. What are the implications of intensive and selective fishing for the stability and productivity of the aquatic ecosystem? One is that the increasing scarcity of larger fish may be associated with a concomitant rise in abundance of the smaller ones that are their usual prey.
Size-structured models help us interpret cascading impacts on other communities - for example, declines in zooplankton mean less grazing on phytoplankton, whose populations may therefore increase - and on a variety of other complex feedbacks in ecosystems. An important aspect explored in Body Size is the potential effect on nitrogen-cycling of removing larger organisms because they excrete more than smaller ones.

In the summary chapter - 'Body size in aquatic ecology: Important, but not the whole story' - the editors provide a frank assessment of where theory and observations regarding metabolic concepts in ecology align, and where they have yet to do so. For example, sev- eral chapters question whether the relationship between body size and metabolic rate is fixed, and meta-analyses of field data point to some intriguing variations. Mid-water organisms on average have higher rates of metabolism than those of equivalent size in bottom-dwelling systems, perhaps because of their perpetual movement for predator avoidance. Freshwater invertebrate communities mostly support the fixed relationship, but those from a particular stream type that is replete with nutrients from woody debris, do not. We cannot yet say whether these anomalies are exceptions that prove the rule, or the result of one-off measurements or of an oversimplistic model of relationships governing disparate aquatic ecosystems.

Research on body size as an organizing principle in aquatic ecosystems, explored in this fine book, involves useful groupings of subsets of species and ecosystem types. The volume's worth is found in the series of chapters that are thematically organized around developing sub-areas of body size that allow more elaborate interpretation than a single unifying metabolic theory. This approach may need to be broadened if it is to be used to provide a systematic interpretation of the full variety of patterns observed in nature.

Steven A. Murawski is director of scientific programs and chief science adviser at National Marine Fisheries Service, NOAA, Silver Spring, Maryland 20910, USA.

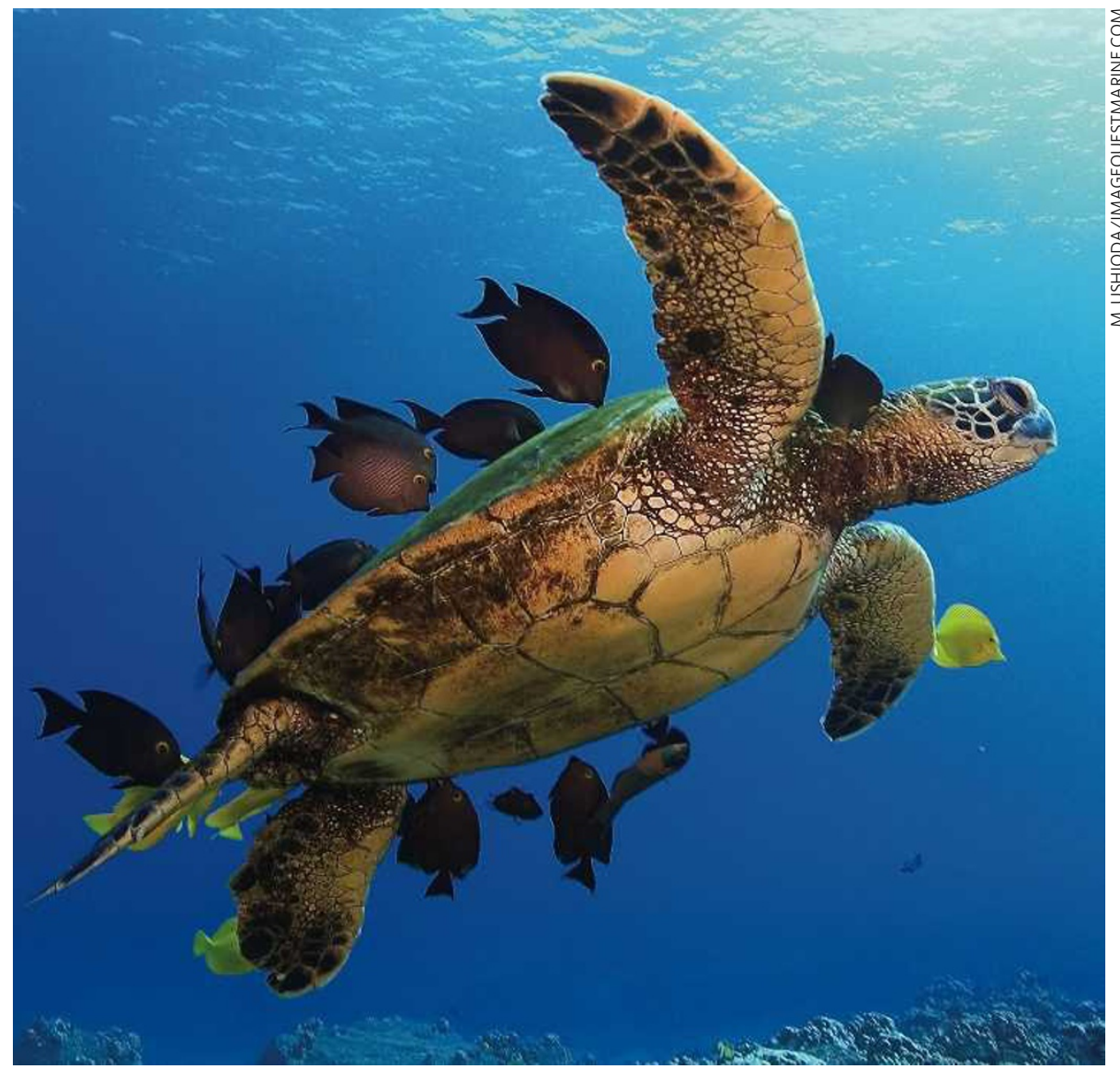

Little and large: cleaner fish set to work on a green sea turtle, in decline because of fisheries' bycatch. 